\title{
DUITSE AMPTELIKE KORRESPONDENSIE IN VERBAND MET DIE VERDEDIGING EN FORTEBOU IN DIE ZUID-AFRIKAANSCHE REPUBLIEK
}

\section{INLEIDING}

In die M.H.A.D.-publikasie Die Fortifikasie van Pretoria. Fort Klapperkop. Gister en Vandag . . .' is op p. 21 vermeld dat, in die loop van die jaar 1896, 'n strategiese terreinstudie van die omgewing van Pretoria gemaak is ${ }^{2}$. Tewens is, in dieselfde werk, m: lding gemaak van 'n geskil tussen kontrakteur H. C. Werner en generaal P. J. Joubert oor die bou van Fort Daspoortrand ${ }^{3}$.

Sowel in eersgenoemde as in laasgenoemde geval bestaan daar, sowel in die geval van 'n uitgebreide strategiese terreinstudie van die hand van ingenieur Von Dewitz as waar dit die geskil tussen boukontrakteur Werner en generaal Joubert betref, 'n tweetal insiggewende dokumente. Hulle is ontleen aan konsul-generaal F. von Herff se amptelike korrespondensie aan die toenmalige Duitse Rykskanselier Chlodwig Fürst zu Hohenlohe-Schillingsfürst (1819-1920)4.

Dié korrespondensie behels die volgende briewe:

a. Konsul-generaal F. von Herff - Rykskanselier Fürst zu HohenloheSchillingsfürst. Pretoria, 17 Augustus 1896.

b. Die bylae „Einiges über die Verteidigung von Transvaal," van die hand van ingenieur Von Dewitz, en gedateer Pretoria, Augustus 1896.

c. Konsul-generaal F. von Herff - Rykskanselier Fürst zu HohenloheSchillingsfürst, Pretoria, 28 Maart 1897.

Ongetwyfeld is die belangrikste van bogenoemde argivalia die militêre beskouings van ingenieur Von Dewitz aangaande die verdediging van die Zuid-Afrikaansche Republiek deur die bou van verdedigingswerke, waarvan die gedeeltelik uitgevoerde fortegordel rondom Pretoria as die belangrikste beskou kan word. Hiier volg die tekste van die betrokke insiggewende briewe, saam met vertalings in Afrikaans en Engels.

\section{TEKSTE EN VERT ALINGS}

Pretoria den 17. August 1896.

Euerer Durchlaucht beehre ich mich an bei einem von dem militärischen Leiter der Befestigungsarbeiten bei Pretoria, Herrn von Dewitz, entworfenen Aufzeichnung über die bei der Befestigung des Landes zu beobachtenden strategischen Gesichtspunkte zur hochgeneigten Kenntnisnahme gehorsamst vorzulegen.

(gez.) Von Herff.

An:

Seine Durchlaucht

Den Herrn Reichskanzler

Fürsten zu Hohenlohe-Schillingsfürst. 


\section{Einiges über die Verteidigung von Transvaal}

Seit Beginn dieses Jahres ist, besonders hervorgerufen durch den Jameson Einfall, die Frage der Verteidigung des Landes durch Anlage von Befestingungswerken in den Vordergrund der militärischen Gesichtspunkte im Transvaal getreten. Nachdem man gesehen hatte, dasz man auch mitten im Frieden plötzlich durch bewaffnete Macht überfallen werden kann, wurde man gezwungen, sich gegen derartige Eventualitäten zu schützen. Da die einzige stehende Truppe früher aus hunderd, jetzt aus vierhunderd Mann Artillerie besteht, so ist es einem an der Grenze versammelten feindlichen Korps leicht möglich, weit in das Land hereinzudringen, bevor sich ihm eine aus Bürgern aufgerufene Macht entgegenstellen kann. Nach der Westgrenze beträgt die Entfernung von Pretoria Z.B. nur ca 160 Engl. Meilen. Ausserdem ist ein Zusammenziehen der Bürgertruppe unter solchen Umständen natürlich schwierig und gefährlich.

Mit Bezugnahme auf die geografische Lage von Transvaal muss man als hauptsächlich zu erwartenden Gegner England ansehen mit der Kolonie Natal im Süden von Transvaal und dessen ganze Nord- und Westgrenze mit den verschiedenen Protektoratsgebieten umfassend ansehen. Man muss nun in die Folgenden Zurgrunde legen, dasz im Kriegsfalle, Transvaal auf sichselber angewiesen ist. Tritt der Frei Staat ihm zu Hilfe, so ist dies natürlich ein grosser Vorteil, doch darf man bei der Kriegsvorbereitung nicht darauf rechnen sondern seine Verteidigung in sich selber suchen und finden.

Seine Operationbasis wird der Feind jedenfalls in der Nähe der Eișenbahnlinis legen und dies um so mehr als die Transportverhältnisse im Lande immer schlechter werden und einer traurigen Zukunft entgegengehen, denn es ist wohl anzunehmen dasz die Rinderpest unaufhaltsam fortschreitet und das Las fast ebenso vom Rindvieh entblöszt wie es weiter im Norden von Ostafrika der Fall ist. Es würde der Transport von Proviand, Munition, etc. ausser per Bahn nur noch per Mauleselwagen besorgt werden können und dasz man die solange als möglich vermeidet, sondern sich an der Eisenbahn hält, ist selbverständlich.

Danach ergeben sich folgende zu erwartende Angriffsfelder:-

(1) Von Süden von Natal her unter Benützung der Eisenbahn, die durch den nördlichsten Zipfel der Kolonie bei Volksrust in das Transvaalgebiet tritt.

(2) Vom Westen her von dem Pretoria am nächsten gelegenen Grenzort Mafeking bis hierher führt die Bahn Z.B. eine weitere Ausdehnung derselben, nach Norden und zwar ein Gutes Stück der Transvaalgrenze folgend, ist in Ausführung begriffen.

Die Operationsbasis des Angreifers kann hier deshalb im Zukunft leicht verschoben werden und man wird hier einem weiteren Angriffsfeld gegenüberstehen, bes,onders wenn noch in weiterer Zukunft die Bahn über Beira nach Salisbury und vion dort eventuel wieder nach Süden angelegt sein wird. Letzteres steht jedoch wohl noch in der ziemlich weiteren Ferne und die Bahn, die von der Kapkolonie über Mafeking nach Norden führt oder führen wird, geht in ihrer ganzen Länge so nahe an der Transvaalgrenze entlang, dasz es wohl einem Boerdetachement leicht sein soll dieselbe auf einzelnen wichtigen Stellen zu zerstören und so die Zufuhr von Proviand u.s.w. abzuschneiden. Deshalb wird ein Angriffkorps seinen Ausgangspunkt so wenig wie möglich nach Norden schieben, jedenfalls nicht über Mafeking hinaus. Dasz man einzelne kleinere Truppe von Norden her über die Grenze bildenden Limpopo zu erwarten hatt, musz wohl angenommen werden, coch können dies keine besondere grosse Truppenkörper sein, da sie ungesunde und wenig bewohnte Gegenden zu passieren hätten, und wie gesagt, die Mitfähr von Lebensmitteln, etc., eine rucht schwierige wäre. 
(3) Von Osten her musz man sich noch darauf gefasst machen dasz (eventuel) der Durchzug durch das portugiesische Gebiet über Delagoa bay faciert werden könnte, um auch die nach Pretoria fährende Eisenbahnlinie zur Operationsbasis zu benutzen.

(4) Für den Fall, das der Frei Staat sich mit Transvaal verbindet, durch den ersten Anfall des Feindes aber zurückgedrängt wird, oder auf dem Transvaalgebilt seine Streitkräfte zusammenziehen kann, ist eine Sicherung der Eisenbahnlinie über den Vaalflusz notwendig.

Die Angriffsrichtung wird von allen Seiten auf Pretoria als den Sitz der Regierung und den Stapelplatz aller Kriegsvorräte und in zweiter Linie auf Johannesburg, dem Industriencentrum und dem Sitz unruhiger Elemente, die sich eventuel einer Invasion anschlüszen würden, gerichtet sein.

Einen solchen von allen Seiten zu erwartenden Angriff kann das Land circa 20000 Bürger gegenüber stellen. Seldverständlich nimmt es aber trotz der erprobten schnellen Mobilizierung derselben doch dem weitläufigen Wohnen der Leute von Lande eine immerhin einige Zeit bis diese Bürger zu Heereskörpern formiert und zusammengezogen sind: Es wurde daher das Verlangen aufgeworfen, zum Schutz der Mobilizierung, zur Sicherung des Landes, gegen Überfälle, zur Verteidigung strategisch wichtiger Punkte und zur Verstärkung der numerisch nur schwachen Macht, Befestigungen anzulegen. Wo sollte man dieselben anlegen? Hatte man die Grenze zu befestigen, oder die Hauptstadt, oder beides, und in solchen Fällen, was zuerst?

Die am meisten zu erwartende Antwort würde lauten: wenn wir unser Land gegen Einfall verteidigen wollen, so müssen wir den Feind verhindern die Grenze zu überschreiten, also zanächst die Grenze zu befestigen.

Jedoch bei den eigentheimlichen Verhältnissen im Lande - keine regulieren Truppen; im Land selbst möglicher Aufstand, der sich in Verbindung setzt mit feindlichen Truppen an der Grenze - und da die Grenzfestigungen doch auch umgeh:n werden können und in schneller unerwarteter Angriff weit in das Land hinein geführt werden kann, so war es vor allen Dingen notwendig den Hauptstadt zuerst zu sichern.

Pretoria von einem Gürtel gutarmierter Forts umgeben, bildet ein verschanztes Lager von solcher Ausdehnung dasz sich ein Boerenheer in volle Sicherheit darin sammeln und von hier seine Operationen unternehmen kann. Ein zurückweichendes Korps findet hier Schutz um sich wieder zu formieren, doch ist es nicht gezwungen hierher zurückzugehen, um Pretoria $\mathrm{zu}$ verteidigen, sondern kann auch ausweichen und dem Feind im offenen Felde wieder gegenübertreten. Während Pretoria ohne Forts gegen einen anrückenden Feind wenigstens durch 10000 Mann verteidigt werden müsste, sind nach Fertigstellung der Befestigungen nur ca 2400 Mann erforderlich, sodass also fast die gesammten Boerentruppen im offenen Felde verwandt werden können. Ein überraschender, in das Land eindringender Gegner kann vielleicht bis vor dem Tore von Pretoria gelingen, hineinzukommen ist ihm aber nicht möglich. Man wird deshalb erkennen dasz vor allen Dingen die Befestigungsanlagen um Pretoria notwendig sind. Zwei Forte sind im Baubegriffen und es ist dringend erforderlich, dasz auch mit den Andern ohne viel Zeitversäumnis vorgegangen wird. So lange der Gürtel nicht geschlossen ist, so lange sie die Geschütze nicht erreichen und sich gegenseitig nicht unterstützen, so lange bleibt das Werk ein Halbes und der ganze Platz ist nicht stärker zu nennen, als der unverteidigte Punkt in der Befestigungslinie, durch den der Feind immer noch sich durchbrechen kann! 
Von groszer strategischer Bedeutung sind dann ferner wie vorher dargelegt die Punkte bei denen die Eisenbahnen die Grenzen überschreiten. Diese müssen unter allen Umständen befestig werden, einmal um als Sperre gegen das Vorrücken feindlicher Truppen unter Benützung des Schienenweges zu dienen, ferner als Stützpunkt für Unternehmungen gegen zu rücken und di` Rückzuglinie einer vorgedrungenen Armee. Solche Sperrforts leisten ausserordentliche Dienste, können ganze Armeen aufhalten und durch die Unternehmungen von ihnen aus dem Feind zur Umkehr und zur Belagerung zwingen, wodurch der Feldarmee ein grosser Teil Truppen gegenüber einer kleinen Schar Błlagerter entzogen wird. Die zwei wichtigsten derartig zu befestigenden Punkte sind Volksrust und Komatipoort, und in zweiter Linie, Vereeniging.

Es bleibt dann noch die Angriffsseite von Mafeking ze b’rücksichtigen. Wenn auch von dieser Seite keine Eis,enbahn in das Land hineinführt, so ist dies doch ein sehr warscheinliches Angriffsfeld, auf welchem der Feind seine Truppen sehr günstig entwicklen kann, es ist deshalb sehr angebracht auch hier vielleicht in der Gegend von Ottoshoop oder auch auf zwei Stellen südlich und nordlich des Witwatersrands etwa bei Zeerust und in der Gegend von Lichtenburg Sperrforts anzulegen. Weiter nach Norden scheinen Befestigungen wie vorher gesagt vorläufig nicht unbedingt notwendig. Später mit der Entwicklung von Communicationen in Mashonaland und Matabeleland wird das Bedürfnis danach vielleicht mehr hervortraten.

Transvaal mit Befestingungsanlagen wie in dem Vorstehenden dargelegt, mit Gewehren und Geschützen gut bewaffnet und bedient, durch Künderschafterdienst über Bewegungen von Truppen in den Grenzländern unterrichtet und durch gute Organisation für einen Kreig vorbereitet, wird mit Ruhe gegen Feind die Stirn bieten können, und durch seine Stärke Frieden gebieten in Südafrika!

Pretoria, August 1896.

Pretoria 28. März 1897.

Euerer Durchlaucht verfehle ich nicht im Anschlusz an den Dienstbericht No 25 von 15 utmo gehorsamt zu berichten, dasz nich einer mit von dem Staatssekretär in Gegenwart des Staatspräsidentın gemachten ganz vertraulichen Mitteilung zwei weitere Batterien von deutșche Feldgeschützen mit der dazugehörigen Munition für den Preis von $£ 10000$ durch Vermittlung einer hochgestelten Persönlichtkeit in Berlin für die Transvaal-Regierung bestellt worden sind. Bei Nennung des Namens dieser Persönlichkeit bin ich von dem Staatssekretär um strenge Geheimhaltung desselben gebeten worden, was ich auch zugesagt habe. Ich werde deshalb einen besondern Weg wählen müssen um Euere Durchlaucht über die gesagte Persönlichkeit zu unterrichten.

Bezüglich der Fortbauen ist eine ernste Differenz zwischen der deutschen Baufirma H. G. Werner und den Generalkommandanten Joubert dadurch entstanden, dasz der letztere die Erbauung des nächsten Forts den Franzosen zu übertragen gewillt ist und $\mathrm{zu}$ diesem Zwecke den allerdingst gescheiterten Versuch unternommen hat, eins der deutschen Forts der französichen Konkurrenz zu zeigen. Im Folge dieses Verhaltens d:s Generalkommandanten hat sich die genannte deutsche Baufirma beschwerdeführend an den Ausführenden Rat gewandt und eine Abschrift dieser Beschwerde mit der Bitte um Gewährung der konzularische Unterstützung bei mir eingereicht. Da auch mir das Vorgehen des Generalkommandanten umbillig erschien, habe ich kein Bedenkens getragen die erbetene Unterstützung zu gewähren wenn auch in vorsichtiger Form, wie dies das Nähere aus dem gehorsamst beigefügten Anlagen hervorgeht. 
Auf diesem Schritt bin ich von dem Staatspräsidenten zu einer Besprechung der Beschwerde eingeladen worden an der ausserdem der Staatssekretär und der Generalkommandant teilnahmen. Über die politischen Gesichtspunkte, welche hierbei zur Sprache kamen, habe ich mich erwendet in meinem Berichte No 54 vom heutigen Tag gehorsamst Meldung zu machen, und darf ich dennoch hier auf jenem Bericht übermässig Bezug nehmen. Im Bezug der Rechts - und Billigkeitsfrage würde mir vorgelegt, dasz die deutsche Baufirma von $\mathrm{H}$. C. Werner in keiner Weise einen rechtlichen Anspruch auf übertragung weiterer Forte habe was Herr H. C. Werner auch zugab dasz der Generalkommandant nicht die Absicht gehabt habe, der französichen Konkurrenz das deutsche Fort zu zeigen, um dieselbe in die Lage zu setzen hiernach ihre Pläne zu machen. Der Generalkommandant habe von konkurrierender französischer Firma mir im Allgemeinen auf das deutsche Fort zu Grunde liegende System aufmerksam machen wollen, damit sich das zu erbauende Fort, dessen Ausführung aus politischen Gründen den Franzosen übertragen werden müsse, an diesem System anschlüssen könne. Diese Ausrede war indess zu durchsichtig, und verdeckte schlecht die den Deutschen nicht günstige Meinung des Generalkommandanten, dessem französichen Sympathien bekannt sind.

Um es aber nicht zum Bruch zwischen der erregten deutschen Baufirma und der Transvaal-Regierung kommen zu lassen, machte ich den Vorschlag, dasz die Letztere den Deutschen die Erbauung eines weiteren Forts zusichern solle, wenn es nicht zu vermeiden sei das nächste Fort den Franzosen zu übertragen. Dieser Vorschlag mit welchem sich die deutsche Baufirma einverstanden erklärt hat, scheint jetzt von dem Ausführenden Rat in Erwäging gezogen werden zu sollen.

Von diesem Berichte habe ich nicht verfehlt, dem kaiserlichen Herrn Generalkonsul in Kapstadt Mitteilung zu machen.

(gez.) Von Herff.

An Seine Durchlaucht, Den Herrn Reichkänzler, Fürsten zu Hohenlohe-Schillingsfürst.

Pretoria, 17 Augustus 1896.

Dit is vir my 'n eer om 'n plan wat in verband met die strategiese gesigspunte wat by die versterking van die land in ag geneem moet word en deur die militêre leier van die vestingswerke by Pretoria, mnr. Von Dewitz, ontwerp is, dienswillig ter kennisname aan u Hoogheid voor te lê.

(get.) Von Herff.

Aan: Sy Hoogheid, Sy Edele die Rykskanselier, Fürst zu Hohenlohe-Schillingsfürst.

\section{EEN EN ANDER OOR DIE VERDEDIGING VAN TRANSVAAL}

Sedert die begin van 1896 het, veral na aanleiding van die Jameson-inval, die kwessie van die verdediging van die land deur middel van die bou van vestingwerke op die voorgrond van die militêre aandag in Transvaal getree. Dit is veral deur die Jameson-inval na vore geroep. Nadat ondervind is, dat die mens ook in vredestyd skielik deur 'n gewapende mag oorval kan word, is jy gedwing om jou teen sulke gebeurlikhede te beskerm. Omdat die enigste Staandemag vroeër uit 'n 
vyandelike korps wat op die grens saamgetrek is, heeltemal moontlik om ver in die land binne te dring voordat 'n gekommandeerde mag wat uit burgers saamgestel is, teen dié mag kan optree. Pretoria is byvoorbeeld slegs ongeveer 160 Engelse myl van die westelike grens af geleë. Hierbenewens is 'n sametrekking van burgerlike troepe onder dergelike omstandighede natuurlik moeilik en gevaarlik.

Met betrekking tot die geografiese ligging van Transvaal moet Engeland as die vernaamste moontlike teenstander gesien word met Natal in die suide en sy hele noordelike en westelike grens deur die verskillende protektorate omring. 'n Mens moet nou as grondslag aanvaar dat Transvaal, in geval van oorlog, op homself aangewys is. As die Vrystaat hulp verleen, is dit natuurlik 'n groot voordeel, maar tog mag mens nie met die voorbereiding vir oorlog daarop reken nie, maar moet jy die verdediging in jouself soek en vind.

Die vyand se operasiebasis sal in elk geval naby die spoorlyn geleë wees en dit des te meer as die transport-situasie in die land steeds verder versleg en 'n treurige toekoms tegemoet gaan, aangesien dit aanvaar kan word dat die runderpes onkeerbaar verder versprei en die land feitlik eweseer van vee ontbloot sal wees as wat hoërop in die noorde van Oos-Afrika die geval is. Proviand en ammunisie sou, behalwe per spoor, slegs nog per muilwa vervoer kon word. Dat mens dit so lank as moontlik wil vermy, maar by die spoorlyn bly is vanselfsprekend.

Hieruit blyk die volgende verwagte aanvalsvelde:

(1) Van die suide van Natal af deur gebruikmaking van die spoorlyn wat deur die noordelikste punt van die kolonie by Volksrust die Transvaalse gebied binnegaan.

(2) Vanuit die weste vanaf die grensdorp van Mafeking, wat die naaste aan Pretoria geleë is. Tot hier loop bv. 'n verdere uitbreiding van dieselfde spoorlyn na die noorde. Dit volg inderdaad 'n groot deel van die Transvaalse grens en word tans aangelê.

Die operasiebasis van die aanvaller kan dus hier in die toekoms maklik verskuif word en mens sal hier teenoor 'n verdere aanvalsveld staan, veral as in die verdere toekoms die spoorlyn nog oor Beira na Salisbury en van daar af uiteindelik weer na die suide aangelê sal word. Laasgenoemde moontlikheid lê nog redelik in die verre toekoms en die spoorlyn, wat van die Kaapkolonie oor Mafeking na die noorde loop of sal loop, loop in sy hele lengte so na aan die Transvaalse grens langs, dat dit vir 'n afdeling Boere maklik sal wees om die lyn op enkele belangrike plekke te verniel en sodoende die toevoer van proviand, ens. af te sny. Daarom sal 'n aanvalskorps sy uitgangspunt so min as moontlik na die noorde toe, in elk geval nie verby Mafeking nie, verskuif. Dat mens enkele kleinere troepe-afdelings uit die noorde van oor die grens van die Limpopo kon verwag, moet wel aangeneem word. Tog kan dit geen besondere groot troepemag wees nie, omdat dit deur ongesonde en dunbevolkte gebiede sou moet opruk, en soos gesê, sou in so 'n geval die vervoer van proviand, ens. werklik moeilik wees.

3) Van die ooste af moet ' $n$ mens daarop voorberei wees dat, ingeval die deurtog deur die Portugese gebied oor Delagoabaai kon plaasvind, ook die spoorlyn wat na Pretoria gaan as 'n operasiebasis benut kan word.

(4) In geval die Vrystaat hom met die Transvaal verbind maar deur die eerste aanval van die vyand teruggedruk word, of as hy sy strydkragte op die Transvaalse gebied kan saamtrek, is 'n versekering van die spoorlyn oor die Vaalrivier noodsaaklik. 
Die aanvalsrigting sal van alle kante op Pretoria as regeringsetel en die opslagplek van alle krygsvoorrade, en in die twrede plek op Johannesburg, die industriële sentrum en die setel van oproerige elemente, wat uiteindelik by 'n inval sal aansluit, gerig word.

Die land kan ongeveer 20000 burgers teenoor so 'n aanval stel wat van alle kante verwag word. Vanselfsprekend duur dit tog ten spyte van die bewese snelle mobilisasie, vanweë die feit dat die burgers wydversprei woon, nog 'n tydjie alvorens hierdie burgers in leërafdelings ingedeel en saamgetrek is. Daarom ten beskerming van die mobilisasie, die beveiliging van die land teen onverwagte aanvalle, ter verdediging van strategiese belangrike punte en ter versterking van die geringe getalsterkte van die leër, die aanleg van vestings verlang. Waar moet hulle aangelê word?

Moet mens die grense of die hoofstad, of albei, versterk en, in so 'n geval, wat kom eerste?

Die verwagte antwoord sou lui: As ons ons land teen 'n inval wil verdedig, moet ons die vyand verhinder om oor die grense te kom; vervolgens moet ons dus grense versterk.

Waar daar ewenwel, as gevolg van die spesifieke landsomstandighede, geen gereëlde troepe is nie en daar moontlik in die land opstand kan uitbreek en die opstandelinge hulle met vyandelike troepe aan die grens in verbinding stel - en die grensvestings omtrek kan word en 'n vinnige onverwagte aanval tot ver in die land deurgevoer kan word, is dit bo alles noodsaaklik om allereers die hoofstad te beveilig.

'n Pretoria wat omring word deur 'n gordel van goedgewapende forte, vorm 'n verskanste laer van so 'n omvang dat 'n Boereleër met volle vertroue daar kan saamtrek en sy operasies van hieraf kan onderneem. 'n Terugtrekkende korps vind hier skuiling om hom weer te hergroepeer. Dit word egter nie gedwing om hierheen terug te keer om Pretoria te verdedig nie, maar kan ook uitwyk en die vyand in die oop veld ontmoet. Terwyl Pretoria sonder forte deur minstens 10000 man teen die aanvallende vyand beskırm sou moes word, is daar na die bou van die vestings, slegs ongeveer 2400 man nodig sodat bykans die hele Boereleër in die oopveld aangewend kan word. 'n Teenstander, kan met 'n verrassingsinval dalk tot voor Pretoria se toegange kom, maar om die stad binne te dring sal vir hom egter onmoontlik wees. Mens sal dus erken dat die aanleg van vestings veral rondom Pretoria bo alles noodsaaklik is. Twee forte is in aanbou en dit is 'n dringende vereiste dat daar sonder veel tydversuim met die ander voortgegaan word. Solank as die gordel nie gesluit is nie, en solank as die geskut nie oorvleuel nie en mekaar nie aan weerskante ondersteun nie, bly dit halwe werk en is die hele plek niks meer as 'n onverdedigde punt in die versterkingslinie nie, waardeur die vyand nog altyd kan deurbreek.

Van groot strategiese belang is dan verder, soos reeds genoem, die punte waar die spoorlyne oor die grense gaan. Hulle moet onder alle omstandighede versterk word: Eerstens om as 'n versperring teen die opruk van vyandelike troepe wat die spoorweg gebruik, te dien, verder om as 'n steunpunt ten opsigte van teenaanvalle te dien en as agterste linie van 'n oprukkende leër. Sulke versperringsforte lewer buitengewone dienste, kan hele leërs ophou en kan die operasies van die vyand tot omkeer en beleëring dwing. Hierdeur word die vyand se veldleër gedwing om 'n groot hoeveelheid troepe af te sonder in teenstelling tot die klein groepie beleërdes wat hulle opponeer. Die twee belangrikste punte wat op hierdie wyse versterk moet word, is Volksrust en Komatipoort, en in die tweede plek, Vereeniging. 
Dan moet die aanvalskant van Mafeking af nog in aanmerking geneem word. $\mathrm{Al}$ gaan daar geen spoorlyn die land van hierdie kant af binne nie, is dit tog 'n baie waarskynlike aanvalsveld waarop die vyand se troepe baie voordelig kan ontplooi. Dit is derhalwe besonder vanpas om ook hier, dalk in die nabyheid van Ottoshoop of ook op twee plekke ten suide en ten noorde van die Witwatersrand, ongeveer by Zeerust en in die omgewing van Lichtenburg, versperringsforte aan te lê. Verder noord is dit soos reeds geșê, voorlopig beslis nie noodsaaklik nie om verder noordwaarts versterkings aan te lê nie. Later, met die ontwikkeling van kommunikasies in Mashona- en Matabeleland, sal dié noodsaaklikheid daarvoor waarskynlik dringender word.

Transvaal, met vestings soos hierbo uiteengesit, goed voorsien van en bewapen met gewere en kanonne, deur 'n inligtingsdiens ingelig aangaande die bewegings van troepe in die grenslande en deur 'n goeie organisasie voorbereid op oorlog, sal met gerustheid die vyand die hoof kan bied en deur sy mag die vrede in SuidAfrika afdwing.

Pretoria, Augustus 1896.

Pretoria. 28 Maart 1897.

Ek bly nie in gebreke nie om, in aansluiting by die diensberig No. 25 van 15 laaslede, dienswilliglik aan u Eksellensie te berig dat, na 'n volkome vertroulike mededeling, wat deur die staatssekretaris in die teenwoordigheid van die Staatspreșident gemaak is, nog twee batterye Duitse veldkanonne met die daarby behorende ammunisie, teen 'n prys van $£ 10000$, deur bemiddeling van 'n hooggeplaaste persoon in Berlyn, vir die Transvaalse regering bestel is. Deur die Staatssekretaris is ek om streng geheimhouding van hierdie persoon se naam gevra, wat ek ook belowe het. Ek sal dus 'n besondere weg moet kies om u Eksellensie in verband met die genoemde persoon in te lig.

Met betrekking tot die fortebou het daar 'n ernstige meningsverskil tussen die Duitse boufirma H. C. Werner en kommandant-generaal Joubert ontstaan deurdat laasgenoemde ingestem het om die bou van die volgende fort aan die Franse op te dra. Vir hierdie doel is die stellig mislukte poging onderneem om een van die Duitse forte aan die Franse konkurrente te toon. As gevolg van die houding van die kommandant-generaal het die genoemde Duitse boufirma hom met 'n klag tot die Uitvoerende Raad gewend en 'n afskrif van hierdie klag, met die versoek om 'n waarborg van die konsulêre ondersteuning, by my ingedien. Aangesien die optrede van die kommandant-generaal vir my ook onregverdig skyn te wees, het ek geen bedenkinge gehad om die gevraagde ondersteuning nie, sy dit dan in 'n versigtige vorm, soos dit uit die dienswilliglik bygevoegde bylae sal blyk, te verleen nie.

$\mathrm{Na}$ hierdie stap is ek deur die Staatspresident na 'n bespreking van die beswaar uitgenooi, waaraan die Staatssekretaris en die kommandant-generaal ook deelgeneem het. Van die politieke sienwyses wat by hierdie geleentheid ter sprake gekom het, het ek in my berig No. 54 van vandag dienswilliglik melding gemaak en ek mag nogtans hier ter oorvloede na daardie berig verwys. Met betrekking tot die regs- en billikheidsaspekte is aan my verklaar dat die Duitse boufirma H. C. Werner geensins oor 'n regsaanspraak in verband met die oordrag van verdere forte beskik nie. Mnr. H. C. Werner het ook toegegee dat die kommandant-generaal nie van plan was om die Duitse fort aan die Franse konkurrent te toon nie om hom in staat te stel om sy planne daarop te baseer. Die kommandant-generaal het my daarop gewys dat hy die koukurerende Franse firma in die algemeen op die 
basiese sisteem van die Duitse firma opmerksaam wou maak, sodat die fort wat opgerig word en waarvan die uitvoering, as gevolg van politieke redes, aan die Franse opgedra moet word, by hierdie sisteem kan aansluit. Hierdie voorwendsel was tog te deursigtig en het die ongunstige houding van die kommandant-generaal; wie se simpatie teenoor die Franse bekend is, teenoor die Duitsers op 'n swak wyse weggesteek.

Om dit egter nie tot 'n breuk tussen die opgewonde Duitse boufirma en die Transvaalse regering te laat kom nie, het ek voorgestel dat laasgenoemde die Duitsers, as dit nie vermy kan word om die bou van die volgende fort aan die Franse op te dra nie, van die bou van 'n volgende fort verseker. Hierdie voorstel, waarmee die Duitse boufirma saamgestem het, skyn nou deur die Uitvoerende Raad oorweeg te word.

Ek het nie in gebreke gebly om hierdie berig aan Sy Keiserlike Hoogheid se konsul-generaal in Kaapstad, mee te deel nie.

(get.) Von Herff.

Aan:

Sy Hoogheid die Rykskanselier

Fürst zu Hohenlohe-Schillingsfürst
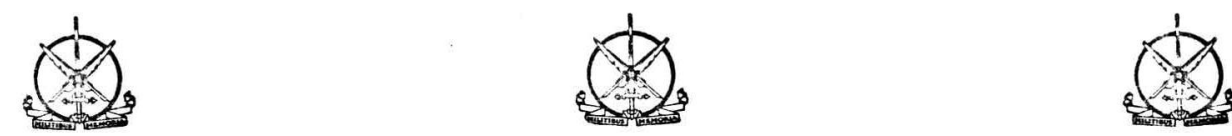


\section{SUMMARY}

This article sheds more light, for the first time, on the contents of official correspondence between the German Consul General at Pretoria ( $F$. von Herff) and the German Imperial Chancellor (Fürst zu Hohenlohe-Schillingsfürst) in 1896 and 1897, regarding engineer Von Dewitz's plans for the defence of the South African Republic by means of the building of forts and, albeit one-sided, on the reasons why the fort Daspoortrand, Pretoria was built by a French firm.

The plans are of particular importance and the reader obtains an insight into German-French economic competition in the South African Republic during the late nineties of the last century. The competition played a role in regard to the building of the forts around Pretoria.
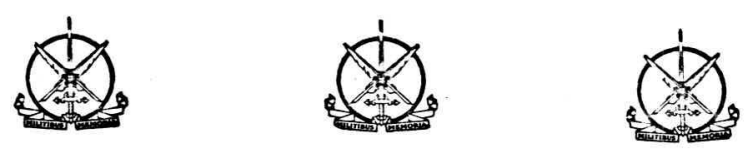

\section{AANTEKENINGE}

1. Pretoria, 1968.

2. P. 25 .

3. Ibid., p. 35 .

4. Volgens H. Herzfeld, Geschichte in Gestalten, deel 2, Frankfurt am Main, 1963, pp. 214-215, was hierdie Suid-Duitse aristokraat o.m. Eerste Minister van Beiere, gesant in Parys (1874-1885). In 1890 het aan hom die hoë onderskeiding te beurt geval om die rykskanselierskap van die Duitse keiserryk te beklee. Tydens sy ampstydperk het hy na toenadering met Rusland gestrewe. Hierdie beleid het, ookal as gevolg van die bekende Kruger-telegram, tot 'n verskerpte teenstelling ten opsigte van Engeland gelei. Die betrokke amptelike korrespondensie, in mikrofilmvorm in die Transvaalse Argief-bewaarplek aanwesig, kom op mikrofilms A. 625 en A. 626 (Akten. Südafrika. Auswärtiges Amt. Abtheilung A.) voor.

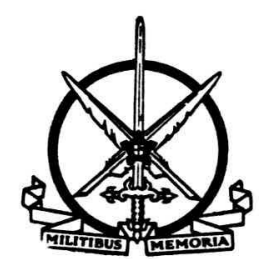

